CIRJE-F-1071

\title{
International Capital Market and Repeated Tax Competition
}

\author{
Satoshi Kasamatsu \\ Graduate School of Economics, The University of Tokyo \\ Hikaru Ogawa \\ The University of Tokyo
}

November 2017

CIRJE Discussion Papers can be downloaded without charge from:

http://www.cirje.e.u-tokyo.ac.jp/research/03research02dp.html

Discussion Papers are a series of manuscripts in their draft form. They are not intended for circulation or distribution except as indicated by the author. For that reason Discussion Papers may not be reproduced or distributed without the written consent of the author. 


\title{
International Capital Market and Repeated Tax Competition*
}

\author{
Satoshi Kasamatsu \\ Graduate School of Economics \\ University of Tokyo \\ E-mail: kasamatsu00@gmail.com \\ Hikaru Ogawa \\ Graduate School of Economics and Graduate School of Public Policy \\ University of Tokyo \\ E-mail: ogawa@e.u-tokyo.ac.jp
}

November 15,2017

\begin{abstract}
We propose an infinitely repeated game of tax competition with an endogenous capital supply. Our results show that the larger the capital supply elasticity to interest rates, the easier it is for interregional tax coordination within a country to be achieved. The capital supply elasticity is lower when countries are less integrated into the international capital market, and vice versa. Thus, our finding suggests that the regions in the country with a lower (higher) degree of integration in the global market are less (more) likely to achieve tax coordination.
\end{abstract}

Keywords: Repeated tax competition, Tax coordination, Endogenous capital supply.

JEL Classification Numbers: H30, H87.

${ }^{*}$ The authors acknowledge the financial support of JSPS Grant nos. 16J02563, 17J07949 and 17 H02533. 


\section{Introduction}

Since the seminal work of Zodrow and Mieszkowski (1986) and Wilson (1986), many studies have examined the inefficiency in the tax competition environment. When a country increases its tax rate, the outflow of the tax base generates a positive fiscal externality. As a result, tax competition induces an inefficiently low tax rate and a low public service level [Wildasin (1989)]. In addition to this, a further source of inefficiency is inherent in the tax competition economy. A change in a country's tax rate affects the price of capital and, thus, other countries' returns on trade in capital, generating a terms-of-trade externality [DePeter and Myers (1994)]. Because the loss in terms of resource allocation is too big to ignore, measures to rectify inefficient tax policies have been sought. ${ }^{1}$

No matter which distortion a government faces, the potential for long-term tax cooperation is well known. Thus, the repeated interaction models of tax competition provide a better perspective on the conditions under which efficient tax coordination is sustainable. ${ }^{2}$ This study follows existing works on the repeated interaction model of tax competition, but focuses on the role of endogenous capital supply, which enables us to examine whether the improvement of access to international capital market enhances or blocks interregional tax cooperation within a country. Previous studies using the repeated game model assume that the total amount of capital with which countries compete is constant, under all circumstances, which means the elasticity of capital supply is always zero. However, this assumption is not necessarily realistic. Considering that the source of capital is savings, it is natural to think that the amount of capital depends on the interest rate. In addition, if we assume some regions in a country compete over capital,

\footnotetext{
${ }^{1}$ For instance, the loss of resources caused by tax competition has been measured as equivalent to $5 \%$ to $8 \%$ of total public expenditure [Wildasin (1989), Parry (2003)].

${ }^{2}$ The first repeated tax competition model was presented by Cardarelli et al. (2002), who show that a smaller disparity between countries makes it easier to achieve tax coordination. Kawachi and Ogawa (2006) extended this model to incorporate the benefit spillovers of public goods. In the latter case, the authors show that the cooperative outcome tends to be realized as the magnitude of the spillovers becomes significant. Taugourdeau (2004) and Catenaro and Vidal (2006) use the Leviathan tax competition model with repeated interactions to show that tax coordination is not sustainable when region sizes are too different. Itaya et al. (2008) isolate the issue of capital allocation from the problem of public goods by assuming there are no public goods in the economy. In this way, they show that a larger disparity between countries makes it easier to achieve tax coordination. Then, Itaya et al. $(2014,2016)$ and Wang et al. (2017) extend the analysis to deal with partial coordination in a threecountry repeated game model. Kiss (2012) shows that introducing an agreement on a lower bound for admissible tax rates triggers a "race to the bottom," thereby worsening the status of all countries. Wang et al. (2014) and Ogawa and Wang (2016) examine how the existence of an equalization transfer system affects the sustainability of tax cooperation. Prior to these studies, Coates (1993) investigated the open-loop equilibrium of a dynamic game of property tax competition.
} 
the amount invested in the country by the international capital market will change according to the domestic interest rate, which is determined by interregional tax competition. As such, we can interpret the magnitude of the capital supply elasticity as a proxy for a country's degree of integration in the international capital market: if the elasticity is zero (infinity), countries are completely isolated from (integrated with) the global capital market.

Some studies on tax competition have incorporated the endogenous supply of capital, finding that it sometimes plays an important role, urging modifications to the accepted and standard views. ${ }^{3}$ While empirical evidence provides mixed results on the magnitude of the capital supply elasticity with respect to the interest rate, it proves that this elasticity is not zero, at least in the long run. Assuming the trend of globalization captured by market integration will continue and, thus, the capital supply of a country will not be constant, this study examines whether the link to the international capital market enhances interregional tax cooperation within a country. The results show that improved access to the international capital market works towards achieving interregional policy cooperation by reducing incentives for wasteful competition within a country. Conversely, the more closed the domestic capital market is, the more each region has an incentive to deviate from the cooperative tax setting.

The rest of this paper is organized as follows. In Section 2, we present the basic model. Then, Section 3 presents a one-shot Nash equilibrium, and Section 4 presents a model of symmetric repeated tax competition. In section 5, the analysis is extended to the case of asymmetric tax competition, in which the asymmetry is captured by the difference between the initial endowments of capital between two regions within a country. Section 6 concludes the paper.

\section{Model}

Environment. This study analyzes a small country that is integrated with the international capital market. The country is very similar to that presented in Petchey and Shapiro (2002) and Petchey (2015), which consists of two symmetric regions $(i=1,2)$, where each region contains homogeneous residents, normalized to 1 . The two regions compete for investment by domestic and overseas investors. We begin by describing the symmetric regions in their simplest

\footnotetext{
${ }^{3}$ For instance, Keen and Kotsogiannis (2002) find that the elasticity of the capital supply critically affects the relationship between horizontal and vertical fiscal externalities in a federation. Eichner and Runkel (2012) verified that capital supply elasticity plays an important role in the efficiency of policymaking in a decentralized economy with mobile capital and spillovers among jurisdictions. Petchey (2015) shows that the efficiency in a decentralized policy setting depends on the capital supply elasticity in a large, open economy with mobile capital and public bads. See also Bucovetsky and Wilson (1991), Yakita (2014), and Wang and Ogawa (2017) for an analysis of tax competition with an endogenous capital supply.
} 
form, deferring a discussion on asymmetric regions until later.

We assume that residents have a high attachment to where they live, and so do not migrate between regions. The fixed amount of initial capital in the country is given by $2 k$, which is owned equally by the residents in the two regions. Thus, a resident in each region owns $k$ units of capital as an initial endowment, which is invested in one of the two regions or in the international capital market. Regional governments compete for the investment by choosing their capital tax rates.

Production. The production of private goods in region $i$ requires capital and labor, along with technology that exhibits constant returns to scale. The per capita production function in region $i$ is given by $y_{i}=f\left(k_{i}\right)$, where $k_{i}$ is the amount of capital per capita used in region $i$. A firm's profit is given by $\pi_{i}=f\left(k_{i}\right)-r k_{i}-t_{i} k_{i}-w_{i}$, where $r$ is the price of capital, $t_{i}$ is the unit tax on capital employment imposed by the regional government, and $w_{i}$ is the wage. Profit maximization gives $w_{i}=f\left(k_{i}\right)-k_{i} f_{k}\left(k_{i}\right)$ and $r=f_{k}\left(k_{i}\right)-t_{i}$, which yields the capital demand function, $k_{i}=k\left(t_{i}, r\right)$.

Domestic capital market. The supply function of capital in the country is expressed in reduced form, and is assumed to be linear in the interest rate: $2 k+c \times\left(r-r^{*}\right)$, where $r$ is the interest rate (rate of return) the country can offer, $r^{*}$ is a given rate of return determined in the world capital market, and $c(\geq 0)$ is the responsiveness of the capital supply to the interest differential, which has a positive relation with the capital supply elasticity with respect to the gap in interest rates [Eichner and Runkel (2012) and Wang and Ogawa (2017)]. The first term represents the supply of capital by the residents in regions 1 and 2, and the second term represents the capital flows to and from the international capital market. If $c=0$, the model reduces to the standard capital tax competition model, in which the capital market of the country is closed to the international market and, thus, the total amount of capital in the two regions is constant. As the parameter $c$ increases, the capital supply responds sensitively to the interest rate. Here, $c$ can be interpreted as a proxy for the connection between the domestic market and the international capital market. The larger the value of $c$, the more the country's market is open to the international market.

The capital market equilibrium for the two-region economy is reached when the sum of the capital demand in the two regions is equal to the total capital supply:

$$
k_{1}\left(t_{1}, r\right)+k_{2}\left(t_{2}, r\right)=2 k+c \times\left(r-r^{*}\right) .
$$

To obtain a clear solution, we specify the form of production as $f\left(k_{i}\right)=\left(A-k_{i}\right) k_{i}$, where $A$ represents the productive efficiency. Under this specification, we have 


$$
\begin{aligned}
r & =\frac{A}{1+c}+\frac{r^{*} c}{1+c}-\frac{4 k+t_{1}+t_{2}}{2(1+c)} \\
k_{i} & =\frac{k}{1+c}-\frac{r^{*} c}{2(1+c)}+\frac{t_{j}-t_{i}+2\left(A-t_{i}\right) c}{4(1+c)}
\end{aligned}
$$

Budget constraints. A resident's preference in region $i$ is given by $U\left(c_{i}\right)=c_{i}$, where $c_{i}$ is the consumption of a private numeraire good. A resident in region $i$ receives labor income $w_{i}\left(=f^{i}\left(k_{i}\right)-k_{i} f_{k}^{i}\left(k_{i}\right)\right)$, a return on her capital investment $r k$, and a lump-sum transfer from the regional government $g_{i}$. Hence, the budget constraint of the resident is given as follows:

$$
c_{i}=w_{i}+r k+g_{i}
$$

The government in each region can only use a unit tax on mobile capital. Thus, the government budget constraint in region $i$ becomes

$$
g_{i}=t_{i} k_{i}
$$

\section{One-shot Game}

\subsection{Nash Equilibrium}

Using Eqs. (4) and (5) with $w_{i}=f^{i}\left(k_{i}\right)-k_{i} f_{k}^{i}\left(k_{i}\right)$ and $r=f_{k}\left(k_{i}\right)-t_{i}$, the resident's utility can be written as $U_{i}=f\left(k_{i}\right)-r\left(k_{i}-k\right)$. This means the resident's utility is equal to the per capita domestic product minus the payment for capital borrowing. The government in each region is assumed to be benevolent, and maximizes the utility of a representative resident of the region by selecting a capital tax rate. The maximization problem is given by

$$
\max _{t_{i}} u_{i}=f\left(k_{i}\right)-r\left(k_{i}-k\right)
$$

where $r$ and $k_{i}$ are given by (2) and (3). Because the capital investment in a region could be made from abroad, the regional governments have an incentive to manipulate the rate of return in the country. Thus, they consider the tax effect on the domestic interest rate, $r$, but are sufficiently small that they cannot affect the rate of return in the international capital market, $r^{*}$. Solving the problem, we obtain the following tax rates in the Nash equilibrium:

$$
t_{1}^{N}=t_{2}^{N}=\frac{\Omega c}{2 c^{2}+4 c+1}
$$

where $\Omega \equiv A-2 k-r^{*}$. In (6), the superscript $N$ denotes the $N a s h$ equilibrium. Substituting (6) into (2) and (3), we obtain the price of capital in the country and the capital allocation in 
the Nash equilibrium:

$$
\begin{aligned}
r^{N} & =r^{*}+\frac{\Omega(2 c+1)}{2 c^{2}+4 c+1}, \\
k_{1}^{N}=k_{2}^{N} & =k+\frac{\Omega(2 c+1) c}{2\left(2 c^{2}+4 c+1\right)} .
\end{aligned}
$$

Here, (8) shows that the regions in the country import capital in equilibrium (i.e., $k<k_{i}^{N}$ ) if $\Omega>0$, where productivity $A$ is sufficiently high and the world interest rate $r^{*}$ is sufficiently small. In contrast, the regions export capital (i.e., $k>k_{i}^{N}$ ) if $\Omega<0$. In the following analysis, we focus on the case of $\Omega>0$, assuming an emerging economy that invites investment from the international capital market. However, we do not exclude $\Omega \leq 0$.

From (6), we find that the regional governments choose a positive (non-positive) tax rate on mobile capital if $\Omega>0(\Omega \leq 0)$. The reason for taking such a sign is simple. When $\Omega>0$, the two regions import capital from the international capital market. In this case, they prefer a low interest rate in order to curtail interest payments. Since the rate of return (interest rate) has a negative relation with the tax rate, as in (2), in order to induce low interest rates, the regional governments have an incentive to use tax to manipulate the interest rate and set positive tax rates. The opposite holds if $\Omega<0$, in which regions export capital. In this case, they choose a negative tax rate in order to increase the interest rate, which yields greater capital income. Furthermore, there is no incentive to manipulate interest rates using tax if the two regions do not export and import capital $(\Omega=0)$.

Using the equilibrium values, the utility in the one-shot Nash game is obtained as

$$
U_{1}^{N}=U_{2}^{N}=\frac{\Omega^{2}(2 c+1)(2 c+3) c^{2}}{4\left(4 c+2 c^{2}+1\right)^{2}}+k\left(\Omega+r^{*}\right)+k^{2} .
$$

\subsection{Tax Coordination}

The condition for a cooperative outcome in the two regions can be found by maximizing the sum of the utilities:

$$
\max _{t_{1}, t_{2}} W=U_{1}+U_{2}
$$

The first-order conditions are

$$
\begin{aligned}
& \frac{\partial W}{\partial t_{1}}=\frac{t_{2}-\left(2 c^{2}+4 c+1\right) t_{1}+2 c \Omega}{4(c+1)^{2}}=0, \\
& \frac{\partial W}{\partial t_{2}}=\frac{t_{1}-\left(2 c^{2}+4 c+1\right) t_{2}+2 c \Omega}{4(c+1)^{2}}=0 .
\end{aligned}
$$

When $c=0$, the optimal choices of $t_{1}$ and $t_{2}$ yield $t_{1}=t_{2}$, suggesting that the common cooperative tax rate is indeterminate. However, if $c>0$, the coordinated tax rate is determined uniquely by

$$
t_{1}^{C}=t_{2}^{C}=\frac{\Omega}{2+c}
$$


suggesting that $\partial t_{i}^{C} / \partial c<0$ if $\Omega>0$, and $\partial t_{i}^{C} / \partial c \geq 0$ otherwise.

Here, we mention two particular features of our result. First, in previous studies that assume a constant capital supply $(c=0)$, the optimal tax rate for cooperation is not determined uniquely [Itaya et al. (2008)]. That is, as long as two governments set identical tax rates, any common tax rate that provides a positive interest rate maximizes the sum of the utilities, because this is tantamount to maximizing the total output of the economy. The condition for total output maximization is that the marginal products of capital are equal, which holds when the two tax rates are identical. However, in this study, in addition to total output maximization, tax coordination is used to attract investment from abroad. Therefore, it is necessary to coordinate the two tax rates to induce the domestic interest rate to the desired level for both regions in a same country. As a result, the interest rate under the cooperative regime is given as follows:

$$
r^{C}=r^{*}+\frac{\Omega}{2+c} .
$$

Second, a comparison of (6) and (10) reveals that $t_{i}^{C}-t_{i}^{N}=\Omega(c+1)^{2}(c+2)^{-1}\left(4 c+2 c^{2}+1\right)^{-1}$, which shows that the equilibrium tax rate is lower (higher) than the cooperative tax rate, $t_{i}^{C}>(<) t_{i}^{N}$, if $\Omega>(<) 0$. The reason why there is a tax gap between $t_{i}^{C}$ and $t_{i}^{N}$ is explained by the existence of externalities: Suppose $\Omega>0$, in which two regions import capital from the international capital market. When a region decreases its tax rate to invite capital, it increases the net-of tax price of capital, $r, \partial r / \partial t_{i}<0$. The region reducing its tax rate takes into account the fact that changing its capital tax increases $r$ and that this will have an impact on its payments for capital imports. However, an increase in $r$ will also have a negative impact on the other region by increasing other region's payment for capital imports, and this is not accounted for by a region changing its capital tax. Therefore, the regional governments choose inefficiently low tax rates in the Nash equilibrium, which means a coordinated increase in capital tax is required. The reason for having $t_{i}^{C}<t_{i}^{N}$, if $\Omega<0$ can be explained in the same way.

Using (10) and (11) with (3), the amount of capital in the cooperative phase is determined as follows:

$$
k_{L}^{C}=k_{S}^{C}=k+\frac{\Omega c}{2(c+2)},
$$

which can be used with (10) and (11) to obtain the utility levels in the cooperative phase:

$$
U_{L}^{C}=U_{S}^{C}=\frac{c \Omega^{2}}{4(c+2)}+k\left(\Omega+r^{*}\right)+k^{2} .
$$

From (9) and (13), we easily find that $U_{i}^{C}>U_{i}^{N}$. 


\section{Repeated Game}

We now consider a repeated game between the two regions. The discount factor of region $i$ is denoted by $\delta_{i} \in[0,1)$. We assume that each region cooperates in tax competition on the current stage if the other region cooperated in the previous stage. If a region defects, then the cooperation between two regions collapses, triggering the punishment stage and indicating that the Nash equilibrium persists forever.

As usual, $\hat{\delta}_{i}$ exists as the critical value of $\delta_{i}$ for region $i$ so that they choose a cooperative tax rate: for all $\delta_{i} \geq \hat{\delta}_{i}$, region $i$ chooses the cooperative tax rate, $t_{i}^{C}$, while for $\delta_{i}<\hat{\delta}_{i}$, the cooperative outcome cannot be supported. The critical value of $\delta_{i}$ is obtained by

$$
\hat{\delta}_{i}=\frac{U_{i}^{D}-U_{i}^{C}}{U_{i}^{D}-U_{i}^{N}}
$$

where $U_{i}^{j}$, for $j=C, D, N$. The superscripts $C, D$, and $N$ denote the utility levels of cooperation, deviation by region $i$, and punishment phases, respectively. Given that the rival region's tax rate is $t_{j}^{C}$, the best-deviation tax rate of region $i, t_{i}^{D}$, maximizes the utility of region $i$ 's residents. The tax rate can then be derived as follows:

$$
t_{i}^{D}=\frac{\Omega\left(2 c^{2}+4 c+1\right)}{(2 c+1)(2 c+3)(c+2)} .
$$

Since $t_{i}^{D}<(>) t_{i}^{C}$, the government in each region deviates from the cooperative tax rate by reducing (increasing) its tax rate when $\Omega>(<) 0$. From (15) and (2)-(3), we obtain the interest rate and the amount of capital in region $i$ as

$$
\begin{aligned}
r^{D} & =r^{*}+\frac{\Omega\left(4 c^{2}+9 c+4\right)}{(2 c+3)(2 c+1)(c+2)}, \\
k_{i}^{D} & =k+\frac{\Omega\left(2 c^{2}+4 c+1\right)}{2(c+2)(2 c+3)},
\end{aligned}
$$

respectively. From (15)-(17), the utility level of region $i$ when region $i$ deviates and region $j$ maintains a cooperative tax rate is

$$
U_{i}^{D}=\frac{\Omega^{2}\left(2 c^{2}+4 c+1\right)}{4(2 c+3)(2 c+1)(c+2)^{2}}+k\left(\Omega+r^{*}\right)+k^{2} .
$$

Substituting Eqs. (9), (13), and (18) into Eq. (14) allows us to obtain the threshold of the discount factor in each region $i$, as

$$
\hat{\delta}_{i}=\hat{\delta}_{j}=\frac{\left(2 c^{2}+4 c+1\right)^{2}}{8 c^{4}+32 c^{3}+39 c^{2}+14 c+1},
$$

where $\lim _{c \rightarrow 0} \hat{\delta}_{i}=1$ and $\lim _{c \rightarrow \infty} \hat{\delta}_{i}=0.5$. From (19), our main finding can be summarized as follows. 
Proposition 1. Tax coordination may be easier to achieve as the responsiveness of capital supply with respect to the interest rate increases: $\hat{\delta}_{i}$ is continuously decreasing in $c$ : $d \hat{\delta}_{i} / d c<0$.

Proposition implies that an improvement of the access of the domestic capital market to (from) the international market increases the possibility that the regions in the country can sustain tax cooperation. The mechanism behind the result can be explained by considering the incentive to deviate from tax cooperation. From (10) and (15), the extent to which each region deviates from a cooperative tax rate is obtained by

$$
t_{i}^{C}-t_{i}^{D}=\frac{2 \Omega(c+1)^{2}}{(2 c+3)(2 c+1)(c+2))},
$$

which gives

$$
\frac{\partial\left(t_{i}^{C}-t_{i}^{D}\right)}{\partial c}=-\frac{2 \Omega\left(4 c^{4}+16 c^{3}+25 c^{2}+20 c+7\right)}{\left(4 c^{3}+16 c^{2}+19 c+6\right)^{2}} .
$$

First, assume $\Omega>0$, in which two regions import capital from the international capital market. Then, (20) and (21) show that each region has incentive to reduce its tax rate from the coordinated level, $t_{i}^{C}>t_{i}^{D}$ but such incentives are reduced as the domestic market becomes more integrated with the international capital market, $\partial\left(t_{i}^{C}-t_{i}^{D}\right) / \partial c<0$. The reason is as follows. When a region deviates and decreases its tax rate to invite capital, the domestic interest rate, $r$, is increased, which causes a large amount of capital inflow when $c$ is large. Increased interest rates and large capital inflows increase payment for capital imports, which discourage the region to deviate from cooperative tax rate. In contrast, when $c$ is zero (or sufficiently small), increased interest rate induced by the tax reduction does not change capital imports (very much). Then, there will be no (less) significant increase in payments for capital imports although there is an increase in payment for the rise in interest rates. Hence, when $c$ is small, the regions do not care much about the increase in payment for capital import, which gives stronger incentive for them to deviate from tax cooperation.

Similar logic applies to the case of $\Omega<0$ because $t_{i}^{D}>t_{i}^{C}$ and $\partial\left(t_{i}^{D}-t_{i}^{C}\right) / \partial c<0$ hold. Therefore, the larger the value of $c$, the easier it is for regional governments to achieve cooperative solutions.

\section{$5 \quad$ Asymmetric Regions}

The analysis in the previous section assumes that all regions in a country have identical technology and initial endowment of capital. This assumption is well justified when analyzing the equilibrium efficiency, because it avoids the distributional issues due to regional disparities. This assumption is also reasonable because the differences between regions in one country are much 
smaller than those between countries. However, some studies have examined the effects on the equilibrium outcome of regional asymmetries in terms of preferences, technology, and initial endowments (Bucovetsky, 1991). In this section, we provide an example that is useful for examining the effects of regional asymmetries on the possibility of achieving tax coordination. This is not merely a formal generalization with which to consider regional asymmetry, but also an examination of the robustness of the results obtained.

The basic setup and notation of the previous sections are preserved here, except for the initial endowment of capital. Now, we assume that the initial capital in the country, $2 k$, is owned by the residents in region 1 , and that the residents in region 2 have no initial capital as an endowment. This assumption makes it possible to simplify expression and to show the effects of regional disparity in the most extreme form. In this setting, the residents of region 1 gain capital income by investing their money in region 2 (and, possibly, abroad), while the residents of region 2 must import capital from region 1 and from international capital markets. ${ }^{4}$ Since the analysis is based on the model in sections 3 and 4 , the description of the results will be brief.

\subsection{Equilibrium}

Nash equilibrium. In the one-shot Nash equilibrium, the tax rates in regions 1 and 2 are chosen as

$$
t_{1}^{N}=\frac{\Omega c}{4 c+2 c^{2}+1}-\frac{k}{c+1} \text { and } t_{2}^{N}=\frac{\Omega c}{4 c+2 c^{2}+1}+\frac{k}{c+1},
$$

respectively. Hence, the capital-rich region chooses a lower capital tax rate than that of the capital-poor region: $t_{1}^{N}-t_{2}^{N}=-2 k /(c+1)<0$. This result is induced by the pecuniary externality or the terms-of-trade effect (DePeter and Myers, 1994; Itaya et al., 2008; Ogawa, 2013). Since the tax rate and the domestic interest rate have a negative relationship, the capital-exporting region 1 attempts to increase the capital price by selecting a lower tax rate. In contrast, the capital-importing region 2 prefers a lower capital price and, thus, selects a higher tax rate.

Using the equilibrium tax rates, we obtain the utility levels in the Nash equilibrium as follows:

$$
\begin{aligned}
U_{1}^{N} & =\Omega^{2} \frac{c^{2}(2 c+3)(2 c+1)}{4\left(4 c+2 c^{2}+1\right)^{2}}+k^{2} \frac{(2 c+1)(2 c+3)}{4(c+1)^{2}}+\Omega k \frac{17 c+16 c^{2}+4 c^{3}+4}{2(c+1)\left(4 c+2 c^{2}+1\right)}+2 k r^{*} \\
U_{2}^{N} & =\Omega^{2} \frac{c^{2}(2 c+1)(2 c+3)}{4\left(4 c+2 c^{2}+1\right)^{2}}+k^{2} \frac{(2 c+1)(2 c+3)}{4(c+1)^{2}}+\Omega k \frac{c(2 c+3)(2 c+1)}{2(c+1)\left(4 c+2 c^{2}+1\right)}
\end{aligned}
$$

The utility gap in the Nash equilibrium is given as

$$
U_{1}^{N}-U_{2}^{N}=\frac{k \Omega\left(7 c+4 c^{2}+2\right)}{(c+1)\left(4 c+2 c^{2}+1\right)}+2 k r^{*}
$$

\footnotetext{
${ }^{4}$ The same situation can be reproduced by assuming the interregional gap in productivity or population.
} 
Cooperative outcome. When two regions cooperate to maximize the total utility in the country, the tax rates must be set as

$$
t_{1}^{C}=t_{2}^{C}=\frac{\Omega}{c+2} .
$$

Without depending on the regional asymmetries, the cooperative tax rate is identical between the two regions. This is simply because the cooperative tax rate is required to maximize the sum of the output and the capital income of the two regions. The utilities in regions 1 and 2 in the cooperative equilibrium are

$$
\begin{aligned}
U_{1}^{C} & =\frac{c}{4(c+2)} \Omega^{2}+k^{2}+k \Omega \frac{c+3}{c+2}+2 r^{*} k, \\
U_{2}^{C} & =\frac{c}{4(c+2)} \Omega^{2}+k^{2}+k \Omega \frac{c+1}{c+2},
\end{aligned}
$$

respectively, which suggest there is the utility gap in the cooperative outcome:

$$
U_{1}^{C}-U_{2}^{C}=\frac{2 k \Omega}{c+2}+2 k r^{*} .
$$

When region 1 deviates. Assume that the government in region 1 deviates from the tax cooperation, while the government in region 2 keeps choosing $t_{2}^{C}$. In this case, the tax rate chosen by region 1 is given by

$$
t_{1}^{D}=\frac{\Omega\left(4 c+2 c^{2}+1\right)-4 k(c+2)(c+1)}{(2 c+3)(2 c+1)(c+2)} .
$$

When region 1 deviates from the tax cooperation, the utility of the residents in region $1, U_{1}^{D}$, is obtained as follows:

$$
U_{1}^{D}=\frac{\Omega^{2}\left(4 c+2 c^{2}+1\right)^{2}}{4(2 c+1)(2 c+3)(c+2)^{2}}+\frac{2 k \Omega\left(14 c+10 c^{2}+2 c^{3}+5\right)}{(2 c+3)(2 c+1)(c+2)}+\frac{4 k^{2}(c+1)^{2}}{(2 c+3)(2 c+1)}+2 r^{*} k,
$$

where the superscript $D$ denotes that region 1 deviates from the tax cooperation, while region 2 maintains the tax cooperation.

When region 2 deviates. Finally, assume that region 2 deviates from the tax cooperation, while the government in region 1 keeps choosing $t_{1}^{C}$. In this case, the tax rate chosen by region 2 is given by

$$
t_{2}^{D}=\frac{4 k(c+2)(c+1)+\Omega\left(4 c+2 c^{2}+1\right)}{(2 c+3)(2 c+1)(c+2)} .
$$

Then, we have 


$$
U_{2}^{D}=\frac{\Omega^{2}\left(4 c+2 c^{2}+1\right)^{2}}{4(2 c+1)(2 c+3)(c+2)^{2}}+\frac{2 k \Omega(c+1)\left(4 c+2 c^{2}+1\right)}{(2 c+3)(2 c+1)(c+2)}+\frac{4 k^{2}(c+1)^{2}}{(2 c+3)(2 c+1)},
$$

where $U_{2}^{D}$ is the utility of the residents in region 2 when region 2 deviates from the tax cooperation, while region 1 chooses the cooperative tax rate.

\subsection{Repeated Game}

Using (22)-(30) with (14), the minimum discount factors to sustain tax cooperation are obtained as follows:

$$
\begin{aligned}
& \hat{\delta}_{1}=\frac{(c+1)^{2}\left(4 c+2 c^{2}+1\right)^{2}[2(c+2) k+\Omega(1+c)]^{2}}{\Delta_{1} \Phi_{1}} \\
& \hat{\delta}_{2}=\frac{(c+1)^{2}\left(4 c+2 c^{2}+1\right)^{2}[2(c+2) k-\Omega(1+c)]^{2}}{\Delta_{2} \Phi_{2}}
\end{aligned}
$$

where

$$
\begin{aligned}
\Delta_{1} & \equiv k(c+2)\left(16 c+8 c^{2}+7\right)\left(4 c+2 c^{2}+1\right)-\Omega(c+1)\left(14 c+39 c^{2}+32 c^{3}+8 c^{4}+1\right) \\
\Phi_{1} & \equiv k(c+2)\left(4 c+2 c^{2}+1\right)-\Omega(c+1)^{3} \\
\Delta_{2} & \equiv k(c+2)\left(16 c+8 c^{2}+7\right)\left(4 c+2 c^{2}+1\right)+\Omega(c+1)\left(14 c+39 c^{2}+32 c^{3}+8 c^{4}+1\right), \\
\Phi_{2} & \equiv k(c+2)\left(4 c+2 c^{2}+1\right)+\Omega(c+1)^{3} .
\end{aligned}
$$

To determine which region has a greater incentive to deviate from tax cooperation, we compare two critical discount factors:

$$
\hat{\delta}_{1}-\hat{\delta}_{2}=\frac{4 k \Omega(2 c+3)(2 c+1)(c+2)\left(4 c+2 c^{2}+1\right)^{2}(c+1)^{3} \Gamma}{\Delta_{1} \Delta_{2} \Phi_{1} \Phi_{2}},
$$

where $\Gamma \equiv \Omega^{2}\left(18 c+41 c^{2}+32 c^{3}+8 c^{4}+2\right)(c+1)^{2}+2 k^{2}\left(16 c+8 c^{2}+5\right)\left(4 c+2 c^{2}+1\right)(c+2)^{2}>$ 0 . From (33), we obtain the following result.

Proposition 2. Assume $\Omega>(\leq) 0$. Then, the capital-poor region 2, which imports capital, has a greater (smaller) incentive to cooperate than the capital-rich region 1 does, $\hat{\delta}_{1}>(\leq) \hat{\delta}_{2}$.

Proposition 2 has a possible link with the result of Itaya et al. (2008), who show that a capital importer has a stronger incentive to cooperate when the cooperative tax rate is positive, but a weaker incentive to do so when the rate is negative. The result shown in Proposition 2 is analogous to their result, but advances the analysis. A major weakness of the result of Itaya et al. (2008) is that the cooperative tax rate is indeterminate. Therefore, they cannot identify the 
level at which the cooperative tax rate is set, or the kind of external environment that is likely to lead regions to choose a positive or negative cooperate tax rate. In our study, we show that the cooperative tax rate is determined uniquely: when the regions in the country import capital from the international capital market $(\Omega>0)$, the cooperative tax rate is positive; however, the rate is negative when the capital owners of the regions in the country invest abroad $(\Omega<0)$. Hence, the analysis succeeds in identifying the environment that determines the level of the cooperative tax rate, and therefore, we can identify the condition that determines which region has a greater incentive to deviate from cooperation.

Furthermore, our analysis in this section makes it possible to show our main result in Section 4 still holds in asymmetric tax competition. That is, the market integration increases the possibility that domestic interregional cooperation is maintained, even if we allow regional asymmetries.

Corollary. Assume region 1 is endowed with $2 k$ units of capital, while region 2 is endowed with nothing. Tax coordination between the asymmetric regions becomes easier as the capital supply elasticity with respect to the interest rate, $c$, increases.

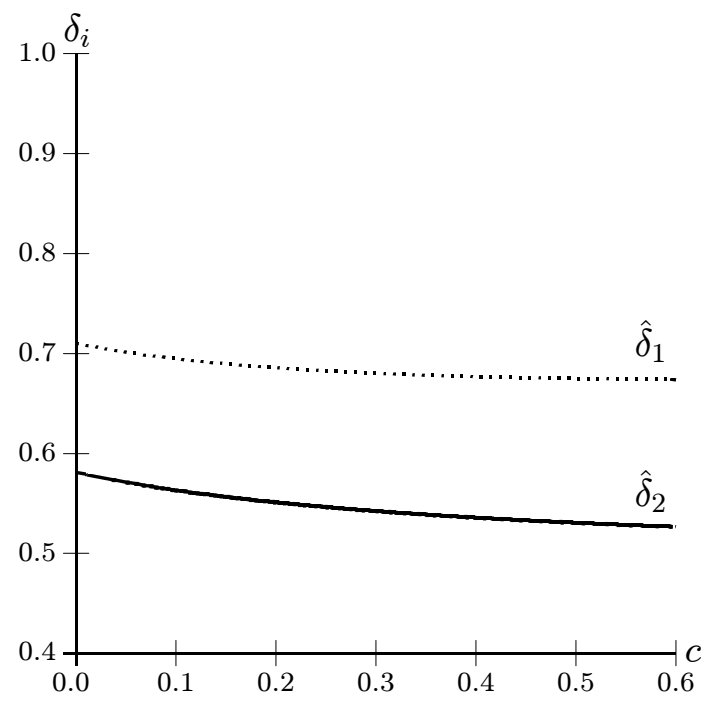

Figure 1. Changes in the critical discount factors, $\hat{\delta}_{i}$, with $c$, when $\Omega>0$.

Note. $\Omega=0.2\left(k=1\right.$ and $\left.A-r^{*}=2.2\right)$ 


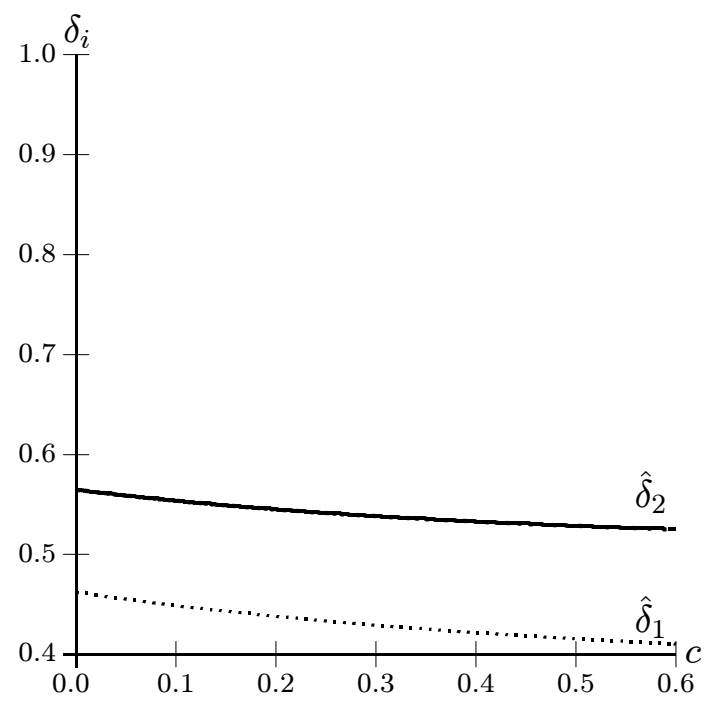

Figure 2. Changes in the critical discount factors, $\hat{\delta}_{i}$, with $c$, when $\Omega<0$.

Note. $\Omega=-0.2\left(k=1\right.$ and $\left.A-r^{*}=1.8\right)$

For reference purposes, Fig. 1 shows the critical discount factor, $\hat{\delta}_{i}$, when $\Omega=0.2>0$. Here, as shown in Proposition 2, the capital-rich region 1 is more likely to deviate from tax cooperation than is region $2, \hat{\delta}_{1}>\hat{\delta}_{2}$. In this case, tax cooperation between the two regions is more likely to be achieved if the possibility of region 1 cooperating increases. Fig 1 shows that $\hat{\delta}_{1}$ decreases as $c$ increases, suggesting that an increase in $c$ enhances the tax coordination between the asymmetric regions.

Fig. 2 shows the critical discount factor, $\hat{\delta}_{i}$, when $\Omega=-0.2<0$. As Proposition 2 suggests, in this case, region 2 is more likely to deviate from tax cooperation than is region $1, \hat{\delta}_{1}<\hat{\delta}_{2}$. Fig. 2 also shows that an increase in $c$ enhances tax coordination by decreasing $\hat{\delta}_{2}$.

Intuitively, a higher value of $c$ means it is more likely that the two regions will cooperate in choosing $t_{i}^{C}$, as explained in Section 4 . First, suppose the target country imports capital from the international capital market, $\Omega>0$. In this case, $t_{1}^{C}>t_{1}^{D}$ and $\partial\left(t_{1}^{C}-t_{1}^{D}\right) / \partial c<0$, meaning that region 1 has an incentive to deviate from the cooperative tax rate by reducing its tax rate, but this incentive becomes weaker as the market integration increases. ${ }^{5}$ If $c$ is sufficiently small (e.g., zero), there is little, or no capital inflow from the international capital market. Thus, region 1 exports its capital to region 2. In this case, region 1 has a significant incentive to increase the domestic interest rate by lowering its tax rate from the cooperative tax level in order to receive higher capital income. However, when $c$ is sufficiently large, there is a significant capital inflow from abroad, and therefore, the export from region 1 to region 2 decreases. Since capital export to region 2 decreases, region 1 receives relatively small capital income, which induces region 1 to

\footnotetext{
${ }^{5}$ See Appendix A.
} 
have less incentive to raise interest rates. The weaker incentive to raise the interest rate means region 1 has less of an incentive to deviate from tax cooperation.

Next, we consider the case of $\Omega<0$. As Proposition 2 shows, region 2 has a greater incentive to deviate from tax cooperation, $\hat{\delta}_{1}<\hat{\delta}_{2}$. This can be explained using a similar mechanism. In this case, since $t_{2}^{D}>t_{2}^{C}$ and $\partial\left(t_{2}^{D}-t_{2}^{C}\right) / \partial c<0$, region 2 has an incentive to deviate from the cooperative tax rate by increasing its tax rate, but that such incentives become weaker as market integration increases. ${ }^{6}$ Since region 2 has no capital endowment, it always imports capital. However, the capital owned by region 1 is more likely to flow out to the international market when $\Omega<0$. In such a case, region 2 has two incentives to manipulate the interest rate: (i) to decrease the domestic interest rate (by increasing the tax rate) in order to reduce the cost of borrowing capital; and (ii) to increase the interest rate (by lowering the tax rate) in order to prevent capital outflows from region 1 to abroad. When $c$ is small, the incentive to increase the tax rate from (i) outweighs the incentive to reduce the tax rate in (ii), because the capital outflow to the international market is not sensitive to a change in the domestic interest rate. In this case, region 2 has a greater incentive to deviate from the cooperative tax rate by increasing its own tax rate. This lowers the interest rate, which benefits region 2 by reducing its interest payments. In contrast, when $c$ is high, region 2 has less of an incentive to deviate by increasing its tax rate, because the capital outflow is sensitive to the change in the domestic interest rate. Therefore, a reduction in the interest rate, accompanied by a tax increase, would have a significant negative impact, causing the outflow of capital from the country to accelerate. Therefore, region 2 has less of an incentive to deviate from tax cooperation by choosing a higher tax rate when $c$ is large.

In all cases, the incentive for tax cooperation increases as the domestic capital market strengthens its ties with the international capital market. Thus, our main result (Proposition 1) is preserved.

\section{Concluding Remarks}

This study proposed a repeated tax competition model with an endogenous capital supply to examine whether a link to the international capital market enhances interregional tax cooperation within a country. The results show that tax cooperation between regions in a country is more likely to be achieved when the country is integrated with the international capital market.

The paper succeeds in presenting the theoretical hypothesis about the effects of integration in international markets on policy coordination within a country. In addition to this, it also contributes to solve an issue faced by previous research: In the repeated tax competition models,

\footnotetext{
${ }^{6}$ See Appendix B.
} 
the cooperative tax rate is not uniquely determined, which causes the problem that makes the analysis of government size and welfare difficult in the cooperative phase (Itaya et al, 2008). In this paper, we propose a model in which the cooperative tax rate is uniquely determined, so that the tractability of repeated interaction model of tax competition is improved.

Previous tax competition studies have argued that inefficiencies in decentralized policymaking increase with tax competition accompanied by market integration, which encourages competition to lower taxes on capital between countries. In contrast, we show that integration with the capital market enhances the incentives for tax coordination within a country. A stronger connection to the international capital market increases the regional incentive to manipulate domestic interest rates, which increases the incentive for the regions in the country to cooperate when setting tax rates.

Our results show that an outside market encourages regional governments within a country to cooperate. That is, because regional governments have a common purpose of manipulating the domestic interest rate to invite investment from the international market, they cooperate to set the tax rate within the country.

\section{Appendices}

Appendix A. When $\Omega>0$, from (24) and (27), we have

$$
t_{1}^{C}-t_{1}^{D}=\frac{2(c+1)[2 k(c+2)+\Omega(1+c)]}{(2 c+3)(2 c+1)(c+2)}>0,
$$

which gives

$$
\frac{\partial\left(t_{1}^{C}-t_{1}^{D}\right)}{\partial c}=-\frac{2\left[\Omega(c+1)\left(13 c+12 c^{2}+4 c^{3}+7\right)+2 k\left(8 c+4 c^{2}+5\right)(c+2)^{2}\right]}{\left(4 c^{3}+16 c^{2}+19 c+6\right)^{2}}<0 .
$$

Appendix B. When $\Omega<0$, from (24) and (29), we have

$$
t_{2}^{D}-t_{2}^{C}=\frac{2(c+1)[2 k(c+2)-\Omega(1+c)]}{(2 c+3)(2 c+1)(c+2)}>0,
$$

which gives

$$
\frac{\partial\left(t_{1}^{D}-t_{1}^{C}\right)}{\partial c}=\frac{2\left[\Omega(c+1)\left(13 c+12 c^{2}+4 c^{3}+7\right)-2 k\left(8 c+4 c^{2}+5\right)(c+2)^{2}\right]}{\left(4 c^{3}+16 c^{2}+19 c+6\right)^{2}}<0 .
$$

\section{References}

[1] Bucovetsky, S. (1991). Asymmetric tax competition. Journal of Urban Economics, vol.30, $167-181$.

[2] Bucovetsky, S., Wilson, J. (1991). Tax competition with two tax instruments. Regional Science and Urban Economics, vol.21, 333-350. 
[3] Cardarelli, R., Taugourdeau, E., Vidal, J.P. (2002). A repeated interactions model of tax competition. Journal of Public Economic Theory, vol.4, 19-38.

[4] Catenaro, M., Vidal, J.P. (2006). Implicit tax co-ordination under repeated policy interactions. Recherches Economiques de Louvain, vol.72, 1-17.

[5] Coates, D. (1993). Property tax competition in a repeated game. Regional Science and Urban Economics, vol.23, 111-119.

[6] DePeter J.A., Myers, G.M. (1994). Strategic capital tax competition: A pecuniary externality and a corrective device. Journal of Urban Economics, vol.36, 66-78.

[7] Eichner, T., Runkel, M. (2012). Interjurisdictional spillovers, decentralized policymaking, and the elasticity of capital supply. American Economic Review, vol.102, 2349-2357.

[8] Itaya, J., Okamura, M., Yamaguchi, C. (2008). Are regional asymmetries detrimental to tax coordination in a repeated game setting? Journal of Public Economics, vol.92, 2403-2411.

[9] Itaya, J., Okamura, M., Yamaguchi, C. (2014). Partial tax coordination in a repeated game setting. European Journal of Political Economy, vol.34, 263-278.

[10] Itaya, J., Okamura, M., Yamaguchi, C. (2016). Implementing partial tax harmonization in an asymmetric tax competition game with repeated interaction. Canadian Journal of Economics, vol.49, 1599-1630.

[11] Kawachi, K., Ogawa, H. (2006). Further analysis on public good provision in a repeated game setting. FinanzArchiv, vol.62, 339-352.

[12] Keen, M., Kotsogiannis, C. (2002). Does federalism lead to excessively high taxes? American Economic Review, vol.92, 363-370.

[13] Kiss, A. (2012). Minimum taxes and repeated tax competition. International Tax and Public Finance, vol.19, 641-649.

[14] Ogawa, H. (2013). Further analysis on leadership in tax competition: The role of capital ownership. International Tax and Public Finance, vol.20, 474-484.

[15] Ogawa, H., Wang, W. (2016). Asymmetric tax competition and fiscal equalization in a repeated game setting. International Review of Economics and Finance, vol.41, 1-10.

[16] Parry, I. (2003). How large are the welfare costs of tax competition? Journal of Urban Economics, vol.54, 39-60. 
[17] Petchey, J.D. (2015). Environmental standards in a large open economy. Journal of Public Economic Theory, vol.17, 461-467.

[18] Petchey, J.D., Shapiro, P. (2002). State tax and policy competition for mobile capital. Economic Record, vol.78, 175-185.

[19] Taugourdeau, E. (2004). Is fiscal cooperation always sustainable when regions differ in size? Lessons for the EMU. Annals of Economics and Statistics, vol.75/76, 11-36.

[20] Wang, W., Kawachi, K., Ogawa, H. (2014). Fiscal transfer in a repeated interaction model of tax competition. FinanzArchiv, vol.70, 556-566.

[21] Wang, W., Kawachi, K., Ogawa, H. (2017). Does equalization transfer enhance partial tax cooperation? International Review of Economics and Finance, vol.51, 431-443.

[22] Wang, W., Ogawa, H. (2017). Objectives of governments in tax competition: Role of capital supply elasticity. International Review of Economics and Finance, forthcoming.

[23] Wildasin, D.E. (1989). Interjurisdictional capital mobility: Fiscal externality and a corrective subsidy. Journal of Urban Economics, vol.25, 193-212.

[24] Wilson, J.D. (1986). A theory of inter-regional tax competition. Journal of Urban Economics, vol.19, 296-315.

[25] Yakita, A. (2014). Capital tax competition and cooperation with endogenous capital formation, Review of International Economics, vol.22, 459-468.

[26] Zodrow, R.G., Mieszkowski, P. (1986). Pigou, Tiebout, property taxation, and the underprovision of local public goods. Journal of Urban Economics, vol.19, 356-370. 